\title{
Foreword: well-being and local resources as the basis for territorial attractiveness
}

\section{Benoît Parent}

The chapters in this book, which presents a state of the art of knowledge about well-being and territorial resources, will stimulate the reader's curiosity by using a transdisciplinary approach.

Well-being. Being well. On the face of it, what could be more subjective, more personal, more immediate? According to the Oxford English Dictionary, well-being is the "state of being or doing well in life; happy, healthy, or prosperous condition; moral or physical welfare (of a person or community)". How does such a topic, in connection with territorial resources, relate to an urban planning agency?

The obvious first reason is the purpose of the multidisciplinary studies that the Agency conducts with regard to issues of mobility, housing, environment, health and economy, among others, that are backed by observations and prospective analyses of lifestyles and whose goal is to enhance public policies. These public policies are aimed at improving the living conditions for everyone, reducing economic and social inequalities and ensuring the greater well-being of those who inhabit and use the territory.

Considered from this perspective and provided that it be "objectified", well-being is a central and even the foundational inter-thematic feature of territories in transition, of the renewal of development models and of a metropolitan and territorial dynamic of solidarity. It is tied to the enhancement of its resources and the cooperation of the actors.

It is a common yardstick, as well as a multidimensional and perfectly cross-cutting regulator, that puts the individual at its centre. And it is as much a key to understanding the territory as it is the first criterion of its attractiveness (we know how important it is to choices regarding both residential and economic settlement, just as it is to the creation of socio-spatial inequalities). Along with others, the Urban Planning Agency is particularly justified in making use of it to shed new light on its territory of study: the greater Grenoble, an area rich in its own tangible and 
intangible resources, which are its common heritage and the cornerstone of its development.

In this work, the diversity of cases shows how the mobilisation of particular local resources can foster sustainable territorial development while improving well-being and social justice. Using this territorial dimension, we can clearly see that both the individualistic dimension of well-being and the classical measurement of development by economic performance alone are overtaken. As a coherent space offering answers to challenges, the territory is also a place of proximity, a space for diagnosis and public debate that makes it possible to elaborate the idea of collective well-being in a shared way and to make it a guide to action. We get to the heart of the matter. To life and societal choices. To political will. To the things to which we attach value. That which cements our living together. That which makes sense and that we have in common: our resources and shared (non-monetary) wealth. Studying and assessing territorial well-being and local resources means being part of a temporal dimension that pre-empts the future and comparing technical expertise with citizen expertise.

The Development Council encourages the greater Grenoble's Territorial Coherence Scheme (SCoT) to take up these issues. The Agency, which plays a pivotal role, is an essential link between the brainstorming partners, by teaming up with the SFR or by mobilising its multidisciplinary scientific council. Since the beginning, it has been involved in Grenoble's IBEST $^{1}$ project to reflect on and create participatory approaches that have led to the development of an indicator of sustainable territorial well-being. The goal? To start with individual well-being and develop a shared vision of the common good. With political and technical actors and researchers, this vision builds a case for this indicator to produce a paradigm shift that mobilises local resources to put economies on track towards an ecological and social transition.

Benoît Parent

Director, Agence d'Urbanisme de la Région Grenobloise

1 IBEST: Indicateurs de Bien-Être Soutenable Territorial (Sustainable Territorial Wellbeing Indicators) 